\title{
Clinical \& etiological evaluation of Pancytopenia: Experience of tertiary care teaching hospital in central India
}

\author{
Negotia $P^{1}$, Saxena R. $S^{2}$, Jagat R. $S^{3}$, Dubey T. $N^{4}$ \\ ${ }^{1}$ Dr Preeti Negotia, Senior Resident, ${ }^{2}$ Dr. Rita Singh Saxena, Assistant Professor, ${ }^{3}$ Dr. R. S. Jagat, Associate \\ Professor, ${ }^{4}$ Dr. T. N. Dubey, Professor, all authors are attached with Department of Medicine, Gandhi Medical \\ College Bhopal, MP, India.
}

Address for Correspondence: Dr. Rita Singh Saxena, Assistant Professor, Department of Medicine, Gandhi Medical College, Bhopal.

\begin{abstract}
Introduction:Pancytopenia is a common clinico-hematological entity. There are significant variations in incidence of disorders causing pancytopenia. Objectives: To evaluate different causes of pancytopenia \& to correlate underlying etiology of pancytopenia with clinical profile. Methods: This prospective observational study was done in the Department of Medicine, Gandhi Medical College \& Hamidia Hospital, Bhopal between July 2014 to Nov. 2015. 70 cases of pancytopenia were included. All participants underwent clinical evaluation and baseline investigations followed by bone marrow examination. Result: Out of 70 patients, $71 \%$ were $<40$ years and male to female ratio of 1.41:1. Most common presentation was fever and weakness. Most common physical findings were splenomegaly seen in 48 cases. Lymphadenopathy was noted in 6 cases.Megaloblastic anaemia (41.4\%) was most common cause of pancytopenia irrespective of age and sex. It was followed by aplastic anaemia, hypersplenism and leukaemia. Together these four accounted for $94.3 \%$ cases. In younger patients common causes after megaloblastic anemia (42.9\%) were aplastic anemia followed by leukemia, hypersplenism, autoimmunity and infection. In older age group common causes were hypersplenism (23.8\%), aplastic anemia, leukemia and infection after megaloblastic anemia. Aplastic anemia was more common in males and hypersplenism in females. Conclusion: In our study megaloblastic anemia is most common cause of pancytopenia in this part of India irrespective of age and gender. Splenomegaly was more common in megaloblastic anemia, hypersplenism and malignancies. Most of the patients without splenomegaly had aplastic anemia.
\end{abstract}

Keywords: Pancytopenia, Splenomegaly, Bone Marrow

\section{Introduction}

Pancytopenia is a common clinico-hematological entity encountered in day-to-day clinical practice. Pancytopenia can be either due to reduction in haematopoietic cell production inthe bone marrow or increased cells destruction either in bone marrow itself or in spleen [1,2]. Hence, pancytopenia is not a disease but triads of findings that may arise from many different disease processes.

There are varying trends in its etiology, clinical pattern, treatment modalities, and outcome in different studies. Various factors encompassing

Manuscript received: $28^{\text {th }}$ October 2017

Reviewed: $6^{\text {th }}$ November 2017

Author Corrected: $14^{\text {th }}$ November 2017

Accepted for Publication: $20^{\text {th }}$ November 2017 geographic distribution and genetic disturbances may cause variations in incidence of disorders causing pancytopenia in different studies. Best possible diagnostic approach is still evolving for this entity. Not much work has been reported regarding various causes and its clinical presentation from this part of India.

This study is therefore aimed to identify the common causes of pancytopenia in our patients and to correlate clinical features with underlying disease in these patients.

The study will help in framing diagnostic approach to this common clinical problem. 


\section{Objectives}

1. To evaluate different causes of pancytopenia.

2. To correlate the underlyingetiology of pancytopenia with clinical profile.

\section{Material and Methods}

Type of study: Cross-sectional observational study

Place of study: Department of Medicine, Gandhi Medical College \& Hamidia Hospital, Bhopal

Duration of study:July 2014 to Nov. 2015

Sampling: Random

Sample size: 70 patients of pancytopenia

Inclusion criteria: All patients $>13$ years attending outdoor and indoor of medicine department with Pancytopenia. Pancytopenia is defined as $\mathrm{Hb}<12$ gm $\%$, leucocyte count $<4 \times 10^{9} / \mathrm{L}$ and platelet count $<100 \times 10^{9} /$ L. [3]

Exclusion criteria: Patients on cancer chemotherapy and with mono or bicytopenia

Method: All participants underwent a detailed history, clinical examination and investigations which included complete blood picture with red cell indices and peripheral smear, liver function test, renal function test, ultrasound abdomen and bone marrow examination in all cases.cause of pancytopenia was ascertained and data was analysed on SPSS on the basis of etiology, clinical and hematological findings.

\section{Result}

Out of 70 patients, 50 were less than 40 years. Male to female ratio was $1.41: 1$. $80 \%$ patients were vegetarian and $88 \%$ from low socioeconomic strata.

Most common presentation was fever and weakness. Other common symptoms were bleeding, weight loss, bodyache, breathlessness, reduced appetite and vomiting. Most common physical findings were pallor, splenomegaly, hepatomegaly and icterus. Less common findings were sternal tenderness, lymphadenopathy and hematuria.

In this study, megaloblastic anaemia was most common cause of pancytopenia (29 cases) followed by aplastic anaemia (16 cases), hypersplenism (11 cases) and leukemia (10 cases). Together these four causes accounted for $66(94.3 \%)$ cases. Comparison between these four group is summarized in Table 1. Other causes were infections (enteric fever, malarial fever), myeloproliferative disease and SLE.

Amongst megaloblastic anemia cases there was slight male preponderance. Splenomegaly was present in 23/29 cases. MCV was more than $100 \mathrm{fl}$ in more than $85 \%$ of cases. Hypersegmented neutrophils were seen in smear in more than $50 \%$ cases. Bone marrow was diagnostic. Aplastic anemia was more common in younger age group. There was significant male preponderance. Although spleen size was expected to be normal mild splenomegaly was present in $4 / 16$ cases.

Pancytopenia was severe compared to megaloblastic anemia. Majority of patients had normocytic normochromic anemia. Some had macrocytosis. There was relative lymphocytosis in most. Bone marrow was diagnostic.

In hypersplenismaga in there was slight male preponderance. Majority of patients had normocytic normochromic anemia. Bone marrow was hypercellular with reversal of M:E ratio.

Haematopoetic neoplasms were more common in younger males. Splenomegaly was present in 7/10 cases. Majority of patients had normocytic normochromic anemia. Occasional immature cells including myeloblast were seen in smear in almost all cases. Bone marrow was diagnostic.

Less common causes of pancytopenia in this study were infections, autoimmune diseases and myelodysplasia. Typhoid and malaria were infections identified. Bone marrow was hypercellular in malaria but hypocellular in enteric fever. One patient had classical SLE with positive ANA. Bone marrow was hypercellular. 
Original Research Article

Table-1: Comparison between different etiologic groups of pancytopenia.

\begin{tabular}{|c|c|c|c|c|}
\hline & $\begin{array}{c}\text { Megaloblastic } \\
\text { Anemia }\end{array}$ & $\begin{array}{l}\text { Aplastic } \\
\text { Anemia }\end{array}$ & Hypersplenism & Leukemia \\
\hline $\begin{array}{l}\text { Total number of cases } \\
\text { (n) }\end{array}$ & 29 & 16 & 11 & 10 \\
\hline Age $<40$ yrs (n) & 21 & 12 & 6 & 8 \\
\hline Age $>40 y r s(n)$ & 8 & 4 & 5 & 2 \\
\hline Sex ratio(M:F) & $1.07: 1$ & $4.3: 1$ & $1.2: 1$ & All males \\
\hline Bleeding(n) & 2 & 5 & 1 & 2 \\
\hline Splenomegaly(n) & 23 & 4 & 11 & 7 \\
\hline Lymphadenopathy(n) & 0 & 2 & 1 & 3 \\
\hline Hemoglobin $(\mathrm{gm} \%)$ & $4.4-9.8$ & $3.5-7.5$ & $3.8-8.0$ & $5.5-8.8$ \\
\hline $\begin{array}{c}\text { Total WBC count } \\
\text { (/cc) }\end{array}$ & $3000-4000$ & $1200-4000$ & $2800-4000$ & $2800-3800$ \\
\hline $\begin{array}{l}\text { Platelet count } \\
\text { (thousand/cc) }\end{array}$ & $38-100$ & $18-50$ & $33-100$ & $12-90$ \\
\hline Peripheral smear & $\begin{array}{c}\text { Macrocytic } \\
\text { hypochromic smear, } \\
\text { Hypersegmented } \\
\text { polymorphs }\end{array}$ & $\begin{array}{c}\text { Normocytic } \\
\text { normochromic } \\
\text { smear, relative } \\
\text { lymphocytosis }\end{array}$ & $\begin{array}{c}\text { Normocytic } \\
\text { normochromic } \\
\text { smear, few macro/ } \\
\text { micro }\end{array}$ & $\begin{array}{c}\text { Normocytic } \\
\text { normochromic } \\
\text { smear, occ. } \\
\text { blast }\end{array}$ \\
\hline Bone marrow & $\begin{array}{c}\text { Hypercellular, } \\
\text { megaloblastic } \\
\text { erythropoesis, giant } \\
\text { metamyelocytes }\end{array}$ & $\begin{array}{l}\text { Hypocellular, } \\
\text { prominent } \\
\text { lymphocytes \& } \\
\text { plasma cells }\end{array}$ & $\begin{array}{l}\text { Hypercellular, } \\
\text { reversal of } \mathrm{M}: \mathrm{E} \\
\text { ratio }\end{array}$ & $\begin{array}{c}\text { Hypercellular, } \\
>20 \% \text { blast }\end{array}$ \\
\hline
\end{tabular}

Age wise distribution revealed that in $<40$ years, most common causes were megaloblastic anemia and aplastic anemia followed by leukemia, hypersplenism, autoimmunity and infection. In patients $>40$ years the most common cause was again megaloblastic anemia but followed by hypersplenism, aplastic anemia, leukemia and infection.

Genderwise distribution revealed that in males most common causes were megaloblastic anemia and aplastic anemia followed by leukemia, hypersplenism and infection. Whereas in females most common causes were megaloblastic anemia but followed by hypersplenism, leukemia, aplastic anemia, autoimmunity and infection.

Bleeding in the form of epistaxis, gum bleed, purpura and hematuria was present in 10 cases. In patients presenting with bleeding five had aplastic anemia, two had megaloblastic anemia, two had AML and one hyperslenism.

Splenomegaly was seen in 48cases. In patients with splenomegaly common causes were megaloblastic anemia (23), hypersplenism (11), acute leukemia (7). Lymphadenopathy was noted in six cases. Causes were acute leukemia in three, aplastic anemia in two and hypersplenism in one.

Bone marrow aspiration was done in all. It was hypercellular in 50 cases, hypocellular in 17 cases and normocellular in three cases. Among the hypercellular marrow megaloblastic anemia, hypersplenism, acute leukemia, infection, MPD and autoimmune disorder. Among the hypocellular marrow aplastic anemia was the diagnosis in 16 cases. One case had hypocellular marrow secondary to enteric fever.

\section{Discussion}

Pancytopenia is a common manifestation of varied disease entities. Etiological evaluation of pancytopenia using easily available and less invasive diagnostic tools is very important. Age, gender and clinical presentation do aid in planning investigations in a case of pancytopenia. Most studies especially from western world have reported aplastic anemia as a common cause. On 
the contrary many studiesfrom Indian subcontinent have shown megaloblastic anemia to be a common cause of pancytopenia in this region $[2,4,5,6]$. This seems to reflect the higher prevalence of nutritional deficiency in India. A study from Aden revealed that most common causes of pancytopenia in their patients were malaria and hypersplenism (> $45 \%$ ), followed by megaloblastic anemia (14.7\%), aplastic anemia and acute leukemia [7].

In our study megaloblastic anemia was commonest cause of pancytopenia in all age groups and both genders. Vegetarian diet, poor education and socioeconomic status does play a major role in high prevalence on magaloblastic anemia in this region. 23 out of 29 cases had splenomegaly which was usually mild. Splenomegaly in megaloblastic anemia is due to congestion and extramedullary hematopoesis.

We could not do serum vitamin B12 and Folate levels in our patients due to lack of facility in our institute. We also did not correlate its occurence with diet and socioeconomic profile. This may be the limitation of study. Peripheral smear and RBC indices were diagnostic in most cases. Bone marrow cytology corroborated with peripheral smear and RBC indices in all cases. It is very important to diagnose this entity as it is easily treatable with supplementation of vitamins with drastic improvement in quality of life. These are indeed one of the most fruitful conditions in hematological practice with high patient satisfaction.

Most of the patients of aplastic anemia were male and belonged to younger age group. The hallmarks of the disease were pancytopenia and a hypocellular bone marrow. While spleen size is usually normal in aplastic anemia, mild splenomegaly may be seen rarely due to congestion and superadded infection. Again we did not evaluate underlying cause of aplasia due to aforesaid constraints. Establishing early diagnosis is important as many of the cases can be successfully treated with HSCT or Immunosupressive treatment.

Another common cause identified in our study was hypersplenism. The mechanism of pancytopenia has long been thought to be a combination of hemolysis, sequestration, and premature destruction
Original Research Article

of blood cells. Indeed, up to $90 \%$ of the peripheral platelet mass, $30 \%$ of the red cell mass, and $65 \%$ of granulocytes can be sequestered in a massive spleen [8, 9]. Common causes of hypersplenism prevalent in this area as per literature are tropical splenomegaly, chronic liver disease, hemoglobinopathies, infections and neoplasms like lymphoma. Rare causes may be metabolic and deposition diseases [10]. Pancytopenia and hemolytic complications of underlying disease processes are the commonest indication for splenectomy in cases of hypersplenism [11].

Hematopoietic neoplasms may sometimes present with pancytopenia in both children and adults and acute leukemias are among the most common of these. Fever and bleeding may be present. Organomegaly or lymphadenopathy may or may not be present. Meticulous examination of peripheral smear for immature cells may give a clue. But if there is no obvious cause for pancytopenia bone marrow aspiration must be done early.

Many infections cause bone marrow necrosis and bone marrow suppression alongwith increased peripheral destruction due to persistent congestive splenomegaly [12]. Pancytopenia in enteric fever is mostly due to histocytic hyperplasia in bone marrow, with marked phagocytosis of platelets, leukocytes and RBCs but sometimes due to myelosuppression also as seen in our study. Most of the cases are reversible with treatment of infection. Autoimmune diseases can also present with new-onset pancytopenia, which can have multiple etiologic factors like autoimmune destruction, vasculitis, myelosuppression, inflammation and nutritional deficiency. Indeed, hematologic abnormalities are often part of the diagnostic criteria for such diseases, including systemic lupus erythematosus [13, 14].

Hence, while approaching patients of pancytopenia attention should be paid to demographic details like age and gender. Also clinical characteristics like constitutional symptoms, weight loss, presence of bleeding, organomegaly, lymphadenopathy and sternal tenderness should be taken into account. Serious disorders like aplastic anemia and leukemia may be missed if index of suspicion is not kept high. Bone marrow aspiration should be done early if indicated after baseline evaluation. 


\section{Conclusion}

In our study megaloblastic anemia is most common cause of pancytopenia in this part of India irrespective of age and gender as opposed to most of the western studies. Splenomegaly was singlemost important finding which can give a clue to underlying cause. It is more common in megaloblastic anemia, hypersplenism and malignancies. Most of the patients without splenomegaly haveaplastic anemia. Bone marrow may not be needed in most if proper attention is given to clinical features like organomegaly and lab parameters especially RBC indices and peripheral smears but should never be deferred if there is no diagnostic clue from noninvasive workup as ominous causes like acute leukemia is not uncommon.

\section{What this study adds to existing knowledge?}

Various studies from different parts of world have provided different set of etiologies of pancytopenia. There is paucity of data from this part of India. Hence result of this study will help to develop approach to a case of pancytopenia. Megaloblastic anemia is common and treatable cause of pancytopenia and clues should always be sought from red cell indices and peripheral smear. Also leukemia should never be missed as it can present as pancytopenia in early stages and early detection leads to better treatment response in these cases.

Contribution by different authors: Study was done under able guidance of Dr T N Dubey, Professor and Head of Department Medicine, Gandhi Medical College Bhopal. All authors were actively involved in planning and execution of study at all steps. Data collection and analysis was done primarily by Dr Preeti Negotia and Dr Rita Singh Saxena. Manuscript was written by Dr Rita Singh Saxena and was reviewed by all other Authors.

Compliance with ethical standards- None of the authors have conflict of interest.

All procedures performed in studies involving human participants were in accordance with the ethical standards of the institutional and/or national research committee and with the 1964 Helsinki declaration and its later amendments or comparable ethical standards.
Informed consent was obtained from all individual participants included in the study.

\section{Funding: Nil, Conflict of interest: None} Permission of IRB: Yes

\section{References}

1. Mc Kenzie Sherlyn B. Textbook of haematology. $2^{\text {nd }}$ edition.baltimore : William and Wilkins; 1996 pp 55-87.

2. Khunger JM, Arulselvi S, Sharma U, Ranga S, Talib VH. Pancytopenia--a clinico haematological study of 200 cases. Indian J Pathol Microbiol. 2002 Jul; 45(3):375-9.

3. Jain A, Naniwadekar M. An etiological reappraisal of pancytopenia - largest series reported to date from a single tertiary care teaching hospital. BMC Hematol. 2013 Nov 6;13(1):10. doi: 10.1186 / 2052-1839-13-10.

4. Tilak V, Jain R. Pancytopenia--a clinicohematologic analysis of 77 cases. Indian J Pathol Microbiol. 1999 Oct; 42(4):399-404.

5. Qazi RA, Masood A. Diagnostic evalution of pancytopenia. J rawal med coll, 2002;6 : 30- 33.

6. Khodke $\mathrm{K}$, Marwah $\mathrm{S}$ et al. Bone marrow examination in casesof pancytopenia. JIACM 2001; 2: $55-59$.

7. Gamal A H, Ghada A G. Clinical and hematological manifestations of visceral leishmaniasis in Yemeni children. Turk J Hematol 2009; 26(1): 25-28.

8. Aster RH. Pooling of platelets in the spleen: role in the pathogenesis of "hypersplenic" thrombocytopenia. J Clin Invest. 1966 May; 45(5): 645-57.

9. Jandl JH, Aster RH. Increased splenic pooling and the pathogenesis of hypersplenism. Am J Med Sci. 1967 Apr; 253(4):383-98.

10. Green D, Battifora HA, Smith RT, Rossi EC. Thrombocytopenia in Gaucher's disease.Ann Intern Med. 1971 May; 74(5):727-31. 


\section{Original Research Article}

11. Johnson HA, Deterling RA. Massive splenomegaly. Surg Gynecol Obstet. 1989 Feb; 168 (2): 131-7.

12. Sood R, Roy S, Kaushik P. Typhoid fever with severe pancytopenia. Postgrad Med J. 1997 Jan; 73 (855): 41-2.
13. Keeling DM, Isenberg DA. Haematological manifestations of systemic lupus erythematosus. Blood Rev. 1993 Dec;7(4):199-207.

14. Nesher G, Hanna VE, Moore TL, Hersh M, Osborn TG. Thrombotic microangiographic hemolyticanemia in systemic lupus erythematosus. Semin Arthritis Rheum. 1994 Dec; 24(3):165-72.

\section{How to cite this article?}

Negotia P, Saxena R. S, Jagat R. S, Dubey T. N. Clinical \& etiological evaluation of Pancytopenia: Experience of tertiary care teaching hospital in central India. Int J Med Res Rev 2017;5(11):927-932.doi:10.17511/ijmrr. 2017.i11.02 